\section{Efectos clínicos y estructurales del blanqueamiento dental}

\author{
Clinical and structural effects of dental bleaching
}

\section{Resumen}

El objetivo del presente estudio fue la revisión de la literatura científica actual sobre los riesgos del blanqueamiento dental. Se revisaron varios artículos que trataban el tema de los efectos clínicos y estructurales de este procedimiento. Los principales efectos clínicos son la sensibilidad dentaria y la duración del efecto, como efectos en los tejidos se citan desmineralización del esmalte, disminución de la dureza de la dentina, modificación de la capacidad de adherencia de los macrófagos y de su morfología, también en la capacidad secretora de los fibroblastos y su proliferación. Se concluye aun siendo el blanqueamiento dental un procedimiento conservativo tiene riesgos que hay que tener presente en el tratamiento dental e informar a los pacientes.

\section{Abstract}

The aim of this study was to revise the recently scientific literature about risks of dental bleaching. It has been rèvised several articles which had for subject clinical and structural effects of tooth whitening. The principal clinical effects were tooth sensitivity and longevity of bleaching; as structural effects were seen enamel demineralization, decreasing in dentine hardness, modification of adherence capacity and morphology of macrophages and secretory capacity and proliferation of fibroblasts. In conclusion dental whitening is conservative procedure but have many risks to consider in dental treatment.

\section{Artículo de ReVISIÓN}

\section{Marieta Petkova Gueorguieva de Rodríguez"}

\footnotetext{
1 Departamento Académico de Ciencias Básicas, Patología

* Facultad de Odontologia, Universidad Nacional Mayor de Sar Marcos, Lima, Perú E-mail: mpetkovag@unmsm.edu.pe
}

Palabras clave: biocompatibilidad, blanqueamiento dental, peróxido de hidrógeno

Key words: biocompatibility; Tooth Bleaching; Tooth Whitening; Hydrogen peroxide

\section{Introducción}

Aunque la técrica de blanqueamiento dental fue descrita por primera vez en 1848 utilizando ácido oxálico, seguida por la introducción de la têcnica vital de blanquemiento nocturno en 1989, actualmente los cambios en los estilos de vida con el cada vez más fucrte ingrediente del patrón estético como sinónimo de salud, apoyados fuertemente por los medios de comunicación que muestran la imagen de una perfecta, agradable sonrisa blanca han hecho que tenga una gran demanda por los pacientes. ${ }^{1-3}$

Existen una gran variedad de técnicas y sustancias empleadas para el blanquemientu dental dependiendo si son para coloraciones extrínsecas o intrínsecas; en dientes vitales o no; algunas como pastas dentales, otros como gels amplicables en férulas, cintas polietilénicas adhesivas, pincelado de las superficies dentarias bucales; de autoaplicación nocturna o en el consultorio bajo aislamiento absoluto y otras como depósito intracameral en los dientes despulpados. La presente revisión se dirigió básicamente a las sustancias blanqueadoras usadas para coloraciones intrínsecas, como los peróxidos.
Es obligación nuestra, la vigilancia profesional, acerca de los efectos producidos en los tejidos dentarios y los tejidos bucales cercanos y dar a conocer los riesgos y beneficios del blanqueamiento dental a los pacientes.

\section{Efectos clínicos}

La satisfacción personal de poseer una hermosa sonrisa blanca es el efecto deseado. También estudios señalan efectos antisépticos, de reducción de placa y de reparación de heridas. ${ }^{3} \mathrm{Sin}$ embargo, existen una seric de riesgos como:

La duración del efecto blanqueador es impredecible. En algunos estudios se cita regresión del color al ano en $50 \%$ de los casos y en otros se sugiere repetir el tratamiento cada dos años, manifestandose una duración promedia de uno a tres años para el blanqueamiento interno con peróxido de hidrógeno y perborato de sodio. ${ }^{3}$

La efectividad del blanquemiento depende de cual ha sido la causa de la coloración. El pronóstico es reservado en el caso de que haya sido por materiales de restauración que contienen plata o sinc-eugenol, en dientes de mayor edad, cuando es grande el tiempo transcurrido desde el oscurecimiento del diente. ${ }^{4}$

La inflamación de los tejidos periodontales y la resorción radicular externa y ósea se produce con mayor frecuencia en dientes jóvenes debido al mayor diámetro de los túmulos dentinarios que permiten la penetración del material de blanqueamiento intracoronal de los dientes no vitales hacia los tejidos periodontales..$^{5 \cdot 7}$

La sensibilidad de los tejidos blandos como enrojecimiento en proximidad de los dientes blanqueados o irritación oral muy común en el inicio del procesn se relacionan con la concentración de los peróxidos y la trecuencia de su aplicación ?.

La sensibilidad dentaria postoperatoria, parece estar relacionada con el paso del peróxido de hidrógeno a través del esmalte y dentina, lo que produce ligera irritación pulpar ${ }^{9-11}$

El blanqueamiento tiene efectos nocivos sobre la interfase diente-restauración, disminuyendo las propiedades adhesivas de la restauración; por lo cual se recomienda realizar las restauraciones estéticas una semana después de terminado el proceso de blan- 
queamiento dental, mientras que otros estudios no encuentran un efecto significativo; dependiendo probablemente de la concentración de los peróxidos utilizados ${ }^{12,13}$

\section{Efectos estructurales}

La aplicación del peróxido de carbamida al $10 \%$ ocasiona desmineralización del esmalte, extendida a $50 \mu \mathrm{m}$ bajo de la superficie del esmalte. El pH del gel blanqucador usado fue de 6.9 por lo que la desmineralización no se puede atribuir al $\mathrm{pI}$ bajo, sino posiblemente a reacciones descontroladas de los radicales peróxidos. Por lo tanto se necesita cuidadosa evaluación del uso de blanqueadores en pacientes susceptibles a caries dental y a desgaste dentario. ${ }^{14}$

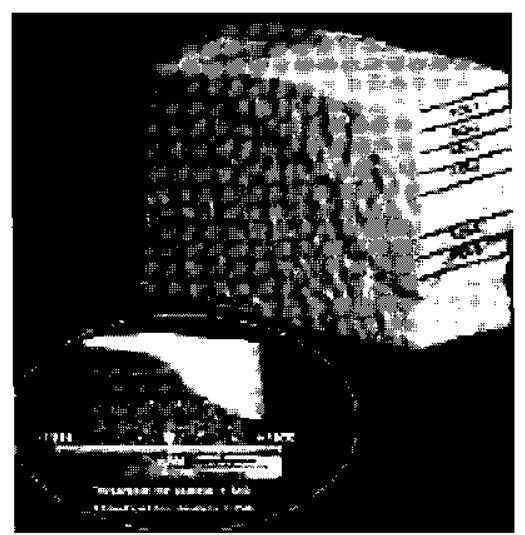

Fig 1: Imagen escaneada de $\mu \mathrm{Ct}$ (microtomografía computarizada), en el circulo a mayor aumento la región de interés con cambio de tonalidad de gris claro a uscuro: Los tejidos mineraliza-dos tienen tonalidad gris más oscuro.

En la evaluación in vitro de un blanqueador dental de peróxido de hidrógeno al $6 \%$ no se encontró diferencia entre la microdureza de la dentina tratada y la dentina con placebo. (Joiner Thakker) Sin embargo, en la dentina tratada con peróxido de hidrógeno al $30 \%$ a $24^{\circ} \mathrm{C}$ por $25 \mathrm{~h}$ se observó alteración en la dentina peri e intertubular, con mayor resistencia de la peritubular, debido a su composición ya que la dentina peritubular es hipermineralizada y carece de colágeno en su matriz orgánica, mientras que el colágeno representa el $92 \%$ de la matriz orgánica de la dentina intertubular, lo que explica la disminución significativa en la dureza de la dentina intertubular. El mecanismo exacto de acción del peróxido de hi- drógeno no se entiende completamente. El peróxido de hidrógeno es potente agente oxidante y también muy ácido con $\mathrm{pH}$ de 2.05. Ambas propiedades parecen participar sobre los cambios que ocurren a nivel de dentina. Debido a esto en el blanqueamiento intracoronal se recomienda el uso de solución combinada de peróxido de hidrógeno al $30 \%$ y perborato de sodio sellados en la cámara pulpar de 3 a 7 días, generalmente repitién-

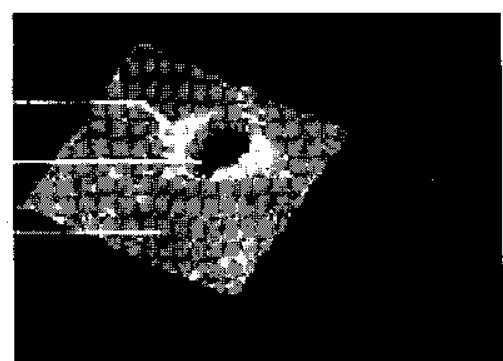

Fig 2: Imagen microscópica de fuerza atómica AFM de dentina peritubular; tubular e intertubular antes de is aplicación de peróxido de hidrógeno

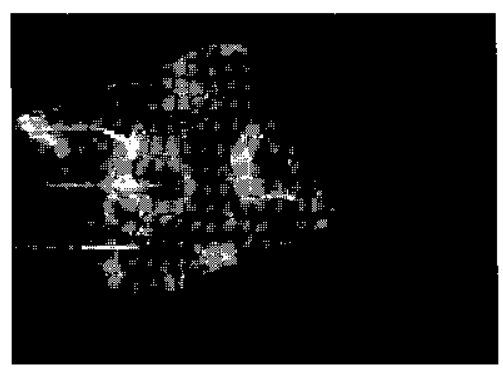

Fig 3: AFM después de la aplicación del peróxido de hidrógeno al $30 \%$ por $24 \mathrm{~h}$ muestra el potente efecto oxidante a nivel de la matriz orgánica de la dentina intertubular

dose este procedimiento varias veces hasta lograr el cambio de color deseado. Es importante también la distancia de aplicación del $\mathrm{pH}$ a la pulpa por la variedad en la densidad tubular y mineral y por la gran capacidad buffer de la dentina. También no es claro si la apicación de cnzimas como la catalasa al final del blanqueamiento revierte estos cambios destructivos ocasionados por el peróxido de hidrógeno. ${ }^{15}$

El gel blanqueador con peróxido de hidrógeno al $6 \%$ no produce efectos en la superficie de los materiales restauradores oro, amalgama, porcelana y composite. ${ }^{16}$

Los macrófagos están implicados en todo el espectro ce las reacciones de defensa. Por lo tarto, después de contacto con un agente agresor, estos fagocitos actúan liberando citoquinas pro-inflamatorios que inician un proceso inflamatorio. Son las células que participan en todas las respuestas del organismo estímulos físicos, químicos o bacterianos. Al evaluar la capacidad de adherencia y la morfología de los macrófagos inflamatorios se observó que aquellos tratados con perborato de sodio no mostraron diferencia alguna con los controles, mientras que los tratados con peróxido de hidrógeno al $30 \%$ presentaron un índice de adherencia aumentado y también alteraciones morfológicas como disrupción de la membrana citoplasmática, presencia de vacuolas citoplasmáticas, núcleos más periféricos y disrupción de la membrana nuclear. Siendo la adherencia el primer paso necesario para el desarrollo de la reacción inflamatoria y la fagocitosis. Estos resultados muestran el potencial citotóxico del peróxido de hidrógeno que es un efectivo blanqueador por su bajo peso molecular y buena difusión a través de los tejidos dentarios (esmalte y dentina), pero tambićn pucde ocasionar daño a los tejidos periodontales y conllevar a reabsorción cervical. ${ }^{7}$

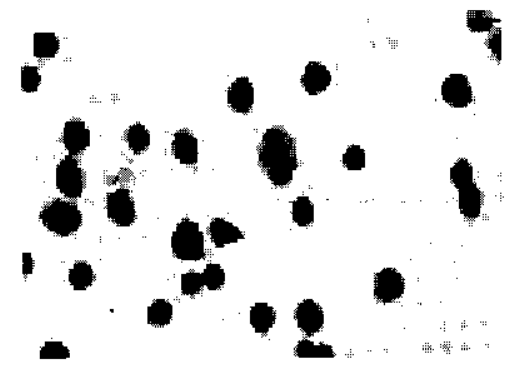

Fig 4: Aspecto normal de macrótagos Perborato de sodio

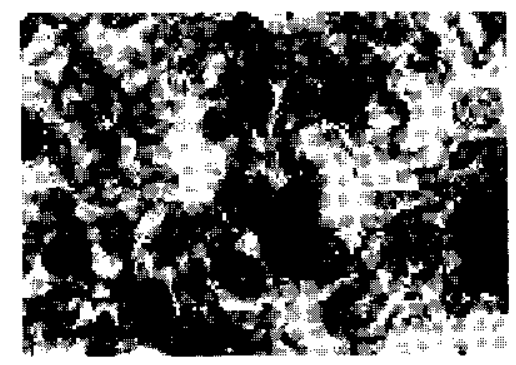

Fig 5: Alteración estructural de macrófages tratados con peróxido de hidró-geno disrupción de membrana citoplas-mática vacuolas, aspecto citoplasmá-tico denso núcieo más periférico

Por otro lado se ha reportado la afección de los fibroblastos gingivales, respecto a su viabilidad, morfología, proliferación y producción de fibronectina y colágeno. ${ }^{3}$ 


\section{Respuestas celulares al estrés oxidativo}

Las pequeñas dosis de oxidantes (el más usado fue peróxido de hidrógeno) produjo incremento de la proliferación de las células mamíleras. Dusis altas causan supresión temporal del crecimiento. El tiempo de supresión de crecimiento es de varias horas y generalmente termina con "células adoptadas». Esto significa que si éstas células son tratadas repetidamente con oxidantes son más resistentes. Como esta adaptación es transiloria, después de un periodo largo la célula es sensible de nuevo. Si posteriormenle se incrementa la dosis, las células pueden entrar en un estadio de suspensión del crecimiento permanente. Estas células no se dividen más, pero cumplen funciones metabólicamente normales. Frecuentemente, este estadio era interpretado como muerte celular, especialmente en los ensayos basados en parámetros de división celular. Si se tratan las células con concentraciones aun más altas de oxidantes, mueren por apoptosis o necrosis. Por lo tanto, hay variedad de respuestas celulares al estrés oxidativo. Se elevan preguntas acerca del efecto de las exposiciones crónicas, el efeclo de varias especies oxidantes y el efecto del lugar de oxidación. La mayoría de cstas preguntas permanecen sin solución y abren un amplio campo de investigación en los próximos años por la relevancia de estas interrogantes para los problemas de salud humana. ${ }^{18}$

\section{Conclusiones}

El blanqueamiento dentario es un tratamiento conservador con resultados satisfactorios. Sin embargo hay que tener en consideración los riesgos que presenta. Entrelas manifestaciones clínicas negativas más frecuentes son la sensibilidad dentaria post-operatoria y la duración del tratamiento. Tam- bién se produce cierta desmineralización del esmalte, disminución de la dureza de la dentina y cambios morfológicos y funcionales en macrófagos y fibroblastos. Esto se relaciona con la concentración y tipo de agente oxidante, siendo entre los más tóxicos el peróxido de hidrógeno.

\section{Referencias}

1.Freedman G. McLaughlin G. Greenwall L. in Bleaching Techniques in restorative dentistry London: Martin Dunitz; 2001, p 139

2.Haywood V. Heymann $H$ Nightguard vital blearhing, Quintessence International 1989; 20: 173-6

3.Lozada O. Garc C. Riesgos y bencficios del blanqueamiento dental. Acta Odontológica Venezolana Vol $38 \mathrm{~N}^{\circ} 1$ Ene 2000

4.Haywood VB.: Historical development of whiteners: clinical safety and efficacy. Aesthetics, 1997, 98-104

5.Baratieri LM., Ritter AV., Monteiro S. Jr., de Andrada MAC., Vieira LCC.: Nonvital tooth bleaching: guidelines to the clinician. Quintessence Int., 1995, 26 (9): 597-08.

6.Madison S., Walton R.: Cervical root resorption following bleaching of endodontically treated teeth. J. Endodon, 1990, 16 (12): 570-574.

7.Montgomery S.:External cervical resorption after bleaching a pulpless tooth. Oral Surg, 1984, 57 (2): $203-$ 206.

8.Collins L. Maggio B. Gallagher A. York M. Schäfer F. Safety evaluation of a novel whitening gel, containing 6 $\%$ hydrogen peroxide and a commercially available whitening gel containing $18 \%$ carbamide peroxide in an exaggerated use clinical study. Journal of Dentistry, 2004 32, 47-52

9.Leonard RH., Haywood VB., Phillips C.: Factores de riesgo en el desarrollo de sensibilidad dentaria e irrigación gingival en los tratamientos de blanqueamiento vital con férulas nocturnas. Quintessence (ed. esp.). 1998, 11: 283-289.

10.Sulieman M. Addy M. Mac Donald E. Rees J. The bleaching depth of a $35 \%$ hydrogen peroxide based inoffice product: a study in vitro Journal of Dentistry, 2005, 33, 33-40

11.Joiner A. Takker G. Cooper $Y$ Evaluation of a $6 \%$ hydrogen peroxide tooth whitening gel on cnamcl and dentine microhardness in vitro. Journal of Dentistry 32, 27-34

12.Barkhordar RA., Kempler D., Plesh O.: Efecto del blanqueamiento de dientes no vitales sobre la microfiltración de restauraciones de composite. Quintessence (ed. esp.), 1998, 11 (4): 209-212.

13.Schemehorn B. Gonzáles-Cabezas C. Joiner A. A SEM evaluation of a 6 $\%$ hydrogen peroxide tooth whitening gel on dental materials in vitro. Journal of Dentistry, 2004, 32, 15-19

14. Efeoglu N Wood D. Efeoglu C. Microcomputerised tomography evaluation of $10 \%$ carbamide peroxide applied to enamel. Journal of Dentistry, 2005, 33, 561-567

15. Chng H.Ramli H. Yap A.Lim C. Effect of hydrogen peroxide on intertubular dentine. Journal of Dentistry, 2005, 33, 363-369

16.Schemehorn B. Gonzáles- Cabezas C. Joiner A. A SEM evaluation of a 6 $\%$ hydrogen peroxide tooth whitening gel on dental materials in vitro Journal of Dentistry, 2004, 32, 35-39

17.Kabbaz K. Moreira M. Japiassú $M$. Machado C. Evaluation of biocompatibility of sodium perborate and 30\% hydrogen peroxide using the análisis of the adherente capacity and morphology of macrofages. Journal of Dentistry, 2005, 33, 155-162

18. Grune T. Oxidants and antioxidative defense. Human \& Experimental Toxicology, 2002, 21, 61-62. 